\title{
Evaluation of Short-term Outcomes of Laparoscopic Heller Cardiomyotomy with Dor Fundoplication Versus Pneumatic Dilatation for Treatment of Achalasia
}

Islam Khaled ( $\nabla$ dr.islam.ahmed@med.suez.edu.eg )

Suez Canal University Faculty of Medicine https://orcid.org/0000-0001-6577-4312

Gad M. Behairy

Ain Shams University Faculty of Medicine

Mohamed Saeed

Cairo University Kasr Alainy Faculty of Medicine

Sara Abdulaziz

Suez Canal University Faculty of Medicine

Leena S. Omar

Suez Canal University Faculty of Medicine

Somia Alshafie

Suez Canal University Faculty of Medicine

Mugahid Elhaj

SGH Jeddah: Saudi German Hospital Jeddah

Mohammed Faisal

Suez Canal University Faculty of Medicine

\section{Research}

Keywords: Achalasia, esophagus, laparoscopic Heller myotomy, pneumatic dilatation

Posted Date: October 26th, 2020

DOI: https://doi.org/10.21203/rs.3.rs-95486/v1

License: (c) (1) This work is licensed under a Creative Commons Attribution 4.0 International License. Read Full License 


\section{Abstract}

Background: Achalasia is a rare esophageal motility disorder of unknown cause. However, the best treatment modality for achalasia is controversial. Treatment consists of disruption of the lower esophageal sphincter, classically either by endoscopic pneumatic dilation or laparoscopic Heller's myotomy combined with an antireflux procedure. The study aim was to compare laparoscopic Heller cardiomyotomy plus Dor Fundoplication with pneumatic dilatation for treatment of achalasia.

Methods: In this interventional study, we included 50 adult patients diagnosed as having achalasia by performing either a barium study or by the absence of peristalsis and impaired relaxation of the lower esophageal sphincter on esophageal manometry. The patients were randomly classified into two groups according to the intervention performed: pneumatic dilation or laparoscopic Heller's cardiomyotomy with Dor's fundoplication(LHCM). Follow-up evaluations were performed after 8 and 16 months.

Results: In total, 50 patients with achalasia and an Eckardt symptom score $>3$ were managed by two different interventions according to their groups.After 16 months of follow up the height of a barium-contrast column after 5 min was significantly lower in the LHCM group than in the pneumatic dilation group. There were no other statistically significant differences in the primary or secondary outcomes(Eckardt score, lower esophageal sphincter, and quality of life) between the two groups.

Conclusion: After 16 months of follow-up, the rates of therapeutic success and number of complications were nearly similar between LHCM and pneumatic dilation. We conclude that either treatment is suitable as an initial treatment for achalasia.

\section{Background}

Esophageal achalasia is a rare primary esophageal motor disorder of unknown cause, characterized by insufficient relaxation of the lower esophageal sphincter (LES) and loss of esophageal peristalsis [1].The disorder occurs with equal frequency in men and women, with an incidence of approximately 0.5 to 1.2 per 100,000 individuals, but recent data have indicated that it increases with age [2,3]. The main classic symptoms of achalasia are dysphagia for solids and liquids, regurgitation of bland undigested food or saliva, heartburn, and weight loss, which often lead to misdiagnosis of achalasia as gastroesophageal reflux disease (GERD) [3, 4]. Diagnosis of achalasia is challenging because of nonspecific symptoms with GERD and the low sensitivity of endoscopic studies[3, 5].

Pneumatic dilatation (PD) and laparoscopic Heller's cardiomyotomy with Dor fundoplication (LHCM) are the common options in the management of esophageal achalasia [4].These treatmentsreduce the pressure gradient across the LES and thus facilitate esophageal emptying bygravity and relief of dysphagia $[4,6$, 7].The treatment of choice for many years was repeated endoscopic PD, which leads to therapeutic success in $70-80 \%$ of patients [6]. The advent of minimally invasive surgery has given rise to substantial interest in this surgical technique, with LHCM combined with anti-reflux treatment, which has become the preferred treatment [8]. 
Randomized controlled trials that compared PD with LHCM have shown that the treatments were equally effective with no significant difference in the risk of complications between groups[5, 6]. Another study showed that LHCM was more effective clinically and monometrically for patients with early stage achalasia than PD, with no significant difference between the two procedures regarding complications [7]. A metaanalysis also suggested that laparoscopic Heller's myotomy may deliver greater response rates than those of PD $\leq 1$ year after treatment [odds ratio (OR), 1.98 for $95 \%$ confidence interval][9].Currently, the choice of treatment depends largely on the physician's knowledge. Moreover, the outcome measures and treatment protocols in previous studies are different, making a comparison among various studies of the success rates of the treatment options problematic [10]. The main aim of this study was to compare LHCM with PD for the treatment of achalasia.

\section{Patients And Methods}

This study included 50 patients who were newly diagnosed with achalasia from June 2016 to June 2018 in three hospitals in two Middle Eastern countries. Written informed consent from all volunteers and approval of each institutional ethics committee were procured. The 50 patients were between the ages of 18 and 70 years and were enrolled on the basis of their diagnosis with achalasia either by esophageal manometry (showing absence of peristalsis and impaired relaxation of the LES with a nadir pressure of $\geq 10 \mathrm{~mm} \mathrm{Hg}$ ) or by a barium study if their Eckardt symptom score was $>3$. The Eckardt score is the sum of regurgitation, dysphagia, weight loss, and chest pain (Table 1) and is higher with patients experiencing more severe symptoms, with 12 being the highest score.

Table 1

Eckardt score: The final score is the sum of all 4 symptoms score, with rang from $0-12$

\begin{tabular}{|lllll|}
\hline Symptoms & Score & & & \\
\hline Dysphagia & $\mathbf{0}$ & $\mathbf{1}$ & $\mathbf{2}$ & $\mathbf{3}$ \\
\hline Regurgitation & None & Occasional & Daily & With every meal \\
Chest pain & None & Occasional & Daily & With every meal \\
Weight loss $(\mathrm{Kg})$ & 0 & $<5$ & $5-10$ & $>10$ \\
\hline
\end{tabular}


Table 2

Demographic data of the two groups

\begin{tabular}{|c|c|c|c|}
\hline \multicolumn{2}{|c|}{$\begin{array}{l}\text { Laparoscopic Heller Cardiomyotomywith Dor Fundoplication } \\
(n=25)\end{array}$} & \multirow{2}{*}{$\begin{array}{l}\text { Pneumatic Dilatation } \\
(\mathbf{n = 2 5 )} \\
47.80 \pm 12.352\end{array}$} & \multirow{2}{*}{$\begin{array}{l}\text { P-Value } \\
0.417\end{array}$} \\
\hline Age & $45.16 \pm 10.371$ & & \\
\hline \multicolumn{4}{|l|}{ Sex $n(\%)$} \\
\hline Male & $11(44.0 \%)$ & $10(40.0 \%)$ & \multirow[t]{2}{*}{1.000} \\
\hline Female & $14(56.0 \%)$ & $15(60.0 \%)$ & \\
\hline \multicolumn{4}{|l|}{ Occupations } \\
\hline Not Working & $14(56.0 \%)$ & $13(52.0 \%)$ & \multirow[t]{2}{*}{1.000} \\
\hline Working & $11(44.0 \%)$ & $12(48.0 \%)$ & \\
\hline \multicolumn{4}{|l|}{ Comorbidity } \\
\hline Hypertension & $3(12.0 \%)$ & $4(16.0 \%)$ & 1.000 \\
\hline Diabetes Mellitus & $5(20.0 \%)$ & $6(24.0 \%)$ & 1.000 \\
\hline Dyslipidemia & $2(8.0 \%)$ & $2(8.0 \%)$ & - \\
\hline Cardiovascular & $2(8.0 \%)$ & $1(4.0 \%)$ & 1.000 \\
\hline \multicolumn{4}{|l|}{ Smoking } \\
\hline Smoker & $6(24.0 \%)$ & $5(20.0 \%)$ & \multirow[t]{2}{*}{1.000} \\
\hline Ex-Smoker & $2(8.0 \%)$ & $1(4.0 \%)$ & \\
\hline Height (cm) & $170.16 \pm 9.035$ & $167.88 \pm 7.886$ & 0.347 \\
\hline Weight (kg) & $73.76 \pm 9.554$ & $72.88 \pm 7.574$ & 0.720 \\
\hline Body Mass Index (kg/m2) & $25.35 \pm 1.114$ & $25.79 \pm 0.914$ & 0.132 \\
\hline Follow-up (months) & $10.08 \pm 3.201$ & $10.52 \pm 2.974$ & 0.532 \\
\hline Dysphagia before treatment & $24.31 \pm 11.260$ & $25.60 \pm 12.857$ & 0.712 \\
\hline Symptoms duration (months) & $46.12 \pm 27.187$ & $52.84 \pm 30.449$ & 0.415 \\
\hline
\end{tabular}

\section{The following data were obtained from each patient:}

- Personal history: age, sex, weight, Body Mass Index (BMI), height, occupation, marital status, smoking, family history, and history of chronic diseases.

- A physical examination and standard hematological and blood chemical work up were also performed for all patients. 
- Upper gastrointestinal endoscopy and esophageal manometry were performed along with barium swallow to evaluate the degree of esophageal stasis before treatment and during follow-up. Four patients out of 50 did not meet the exclusion criteria, including patients unfit for surgery, patients previously treated for achalasia, mega-esophagus (diameter $>7 \mathrm{~cm}$ ), and pseudo-achalasia. The patient selection flow chart is shown in Fig. 1.

Interventions:

\section{- Pneumatic dilation:}

At the esophagogastric junction, a Rigiflex balloon was set and dilated for $1 \mathrm{~min}$ at a pressure of $5 \mathrm{PSI}$, followed by a pressure of $8 \mathrm{PSI}$ for $1 \mathrm{~min}$. All patients underwent two dilations: the first was performed with a 30-mm balloon, and the second was performed 1-3 weeks later with a 35-mm balloon. However, if the Eckardt score was $>3$, a third dilation was performed weeks later with a $40-\mathrm{mm}$ balloon. If the Eckardt score was persistently $>3$, the treatment was considered to have failed.

In the course of the follow-up period, patients with reappearance of symptoms received further dilation with a $35-\mathrm{mm}$ balloon and, if required (i.e., if the Eckardt score remained $>3$ ), a 40-mm balloon. After the second series of dilations, a concluding series of dilations were permitted only if the symptoms reoccurred after 2 years. In addition, if the patient showed recurring symptoms within 2 years after the second dilation series, the treatment was considered to have failed.

\section{- Laparoscopic Heller cardiomyotomy with Dor fundoplication:}

The first step of the procedure was to mobilize the distal esophagus by exposing the diaphragmatic crura and dividing the phrenoesophageal ligament. Myotomy involved the division of all layers of the lower 4$6 \mathrm{~cm}$ of the esophagus abovethe gastroesophageal junction down to the mucosa as well as division of at least 1-2 cm over the stomach. Then, anterior Dor fundoplication of $180^{\circ}$ was performed. During the followup period, if the patients exhibited symptoms of Eckardt score $>3$ after surgery, the treatment was considered to have failed.

\section{Outcomes:}

- The principle end result of the study was to keep the Eckardt score $\leq 3$ during the follow-up period, which stretched to $\geq 18$ months for all participating subjects. Therefore, esophageal manometry to assess the lower esophageal pressure along with barium swallow was performed at every follow-up attempt.

- To evaluate quality of life, the European Organization for Research and Treatment of Cancer diseasespecific questionnaire module for assessing quality of life in patients with esophageal cancer [QLQOES24] and the Short-Form Health Survey [SF-36] were used. The SF-36 mental and physical summary scores assess quality of life by scoring the general aspects of health from $0-100$, with higher scores 
indicating better results of good health [11]. In contrast, the QLQ-OES24 investigates multiple parameters of esophageal function, with lower scores indicating better results [12].

\section{Results}

After exclusions, a total of 50 patients with achalasia and Eckardt symptoms scores $>3$ underwent one of two different procedures. The mean ages of the patients who underwent the LHCM and pneumatic dilation procedures were $45.86 \pm 15.25$ years and $80 \pm 12.35$ years, respectively. The number of females in the LHCM and pneumatic dilation groups were $14(56 \%)$ and $15(60 \%)$, respectively. Furthermore, the mean BMI values were $25.35 \pm 1.11 \mathrm{~kg} / \mathrm{m} 2$ in the LHCM group and $25.79 \pm 0.91 \mathrm{~kg} / \mathrm{m} 2$ in the pneumatic dilation group. The mean symptom durations were $46.12 \pm 27.18$ months in the LHCM group and $52.84 \pm 30.45$ months in the PD group. Differences in occupation, comorbidity, and smoking habits were not significant.

Table 3 shows the primary and secondary outcomes at 8 and 16 months of follow-up. There was a significant difference in the height of the barium-contrast column after 5 minutes between the two groups at 16 months. A comparison of the successful treatmentrates, as shown by Kaplan-Meier survival curves, for PD with LHCM is shown in Fig. 2. 
Table 3

Primary and secondary outcomes at 8 and 16 months of follow-up according to treatment

\begin{tabular}{|c|c|c|c|c|c|c|c|c|c|}
\hline & \multicolumn{3}{|c|}{ Baseline } & \multicolumn{3}{|c|}{ After 8 Months } & \multicolumn{3}{|c|}{$\begin{array}{l}\text { After } 16 \\
\text { Months }\end{array}$} \\
\hline & $\begin{array}{l}\mathrm{LHM} \\
(\mathrm{n}= \\
25)\end{array}$ & $\begin{array}{l}P D \\
25)\end{array}(n=$ & $\begin{array}{l}\mathrm{P} \\
\text { Value }\end{array}$ & $\begin{array}{l}\text { LHM } \\
(n= \\
25)\end{array}$ & $\begin{array}{l}P D(n \\
=25)\end{array}$ & $\begin{array}{l}P \\
\text { Value }\end{array}$ & $\begin{array}{l}\operatorname{LHM} \\
(n== \\
25)\end{array}$ & $\begin{array}{l}P D(n \\
=25)\end{array}$ & $\begin{array}{l}P \\
\text { Value }\end{array}$ \\
\hline Eckardt score & $\begin{array}{l}8.04 \\
\pm 2.5\end{array}$ & $\begin{array}{l}7.08 \pm \\
1.89\end{array}$ & 0.141 & $\begin{array}{l}1.56 \\
\pm 1.08\end{array}$ & $\begin{array}{l}2.04 \\
\pm 1.74\end{array}$ & 0.433 & $\begin{array}{l}1.04 \\
\pm \\
1.060\end{array}$ & $\begin{array}{l}1.72 \\
\pm \\
1.275\end{array}$ & 0.053 \\
\hline \multirow{2}{*}{$\begin{array}{l}\text { Lower } \\
\text { esophageal } \\
\text { sphincter(mmHg) }\end{array}$} & $\begin{array}{l}30.36 \\
\pm 1.4\end{array}$ & $\begin{array}{l}34.20 \pm \\
1.9\end{array}$ & 0.051 & $\begin{array}{l}10.20 \\
\pm 1.3\end{array}$ & $\begin{array}{l}14.00 \\
\pm 1.6\end{array}$ & $0.001^{\star}$ & $\begin{array}{l}10.40 \\
\pm 1.25\end{array}$ & $\begin{array}{l}11.60 \\
\pm 1.89\end{array}$ & 0.240 \\
\hline & 11 & 79 & & 54 & 83 & & 8 & 3 & \\
\hline $\begin{array}{l}\text { Height of barium- } \\
\text { contrast column } \\
\text { after } 5 \text { min (cm) }\end{array}$ & $\begin{array}{l}13.48 \\
\pm 3.4\end{array}$ & $\begin{array}{l}14.72 \pm \\
3.0\end{array}$ & 0.396 & $\begin{array}{l}4.00 \\
\pm 2.34\end{array}$ & $\begin{array}{l}2.96 \\
\pm 2.13\end{array}$ & 0.109 & $\begin{array}{l}3.88 \\
\pm \\
2.522\end{array}$ & $\begin{array}{l}5.48 \\
\pm \\
2.917\end{array}$ & $\begin{array}{l}< \\
0.001 \\
*\end{array}$ \\
\hline \multicolumn{10}{|l|}{ Quality of life } \\
\hline \multirow[t]{2}{*}{ QLQ-OES24 } & $\begin{array}{l}39.60 \\
\pm 2.0\end{array}$ & $\begin{array}{l}36.32 \pm \\
1.4\end{array}$ & 0.101 & $\begin{array}{l}13.00 \\
\pm 1.5\end{array}$ & $\begin{array}{l}14.32 \\
\pm 1.7\end{array}$ & 0.120 & $\begin{array}{l}12.08 \\
\pm 1.47\end{array}$ & $\begin{array}{l}13.68 \\
\pm 1.62\end{array}$ & 0.102 \\
\hline & 00 & 35 & & 81 & 25 & & 0 & 6 & \\
\hline \multicolumn{10}{|l|}{$\begin{array}{l}\text { Short-Form } \\
\text { Health Survey } \\
\text { (SF-36) }\end{array}$} \\
\hline $\begin{array}{l}\text { Physical } \\
\text { component }\end{array}$ & $\begin{array}{l}47.72 \\
\pm 1.3\end{array}$ & $\begin{array}{l}48.08 \pm \\
1.4\end{array}$ & 0.341 & $\begin{array}{l}54.76 \\
\pm 0.7\end{array}$ & $\begin{array}{l}51.92 \\
\pm 1.1\end{array}$ & 0.110 & $\begin{array}{l}53.04 \\
\pm 1.51\end{array}$ & $\begin{array}{l}51.92 \\
\pm 1.28\end{array}$ & 0.051 \\
\hline summary & 70 & 12 & & 79 & 87 & & 3 & 8 & \\
\hline \multirow{2}{*}{$\begin{array}{l}\text { Mental } \\
\text { component } \\
\text { summary }\end{array}$} & $\begin{array}{l}41.60 \\
\pm 1.4\end{array}$ & $\begin{array}{l}43.92 \pm \\
1.8\end{array}$ & 0.451 & $\begin{array}{l}49.44 \\
\pm 1.4\end{array}$ & $\begin{array}{l}49.28 \\
\pm 1.5\end{array}$ & 0.735 & $\begin{array}{l}49.96 \\
\pm 1.33\end{array}$ & $\begin{array}{l}48.52 \\
\pm 1.66\end{array}$ & 0.105 \\
\hline & 14 & 01 & & 74 & 42 & & 8 & 1 & \\
\hline \multicolumn{10}{|c|}{$\begin{array}{l}\text { QLQ-OES24: European Organization for Research and Treatment of Cancer disease-specific questionnaire } \\
\text { module for assessing quality of life in patients with esophageal cancer }\end{array}$} \\
\hline *. Statistically signi & icant $p$ & ue $(p<0$ & & & & & & & \\
\hline
\end{tabular}

Complications of achalasia treatment are outlined in Table 4 . The mucosal tear rate was $4.0 \%$ in the LHCM group, and the number of esophageal perforation complications was $8.0 \%$ in the PD group. The recurrence rates were $24.0 \%$ in the LHCM group and $32 \%$ in the PD group. 
Table 4

Comparison of the preoperative and postoperative complications between the two groups

\begin{tabular}{|llll|}
\hline $\begin{array}{l}\text { Laparoscopic Heller Cardiomyotomy with Dor Fundoplication } \\
(\mathbf{n}=\mathbf{2 5})\end{array}$ & $\begin{array}{l}\text { Pneumatic Dilatation } \\
(\mathbf{n}=\mathbf{2 5})\end{array}$ & P Value \\
\hline Preoperative & $1(4.0 \%)$ & 0 & \\
\hline Mucosal tear & 0 & $2(8.0 \%)$ & 1.000 \\
\hline Esophageal perforation & $2(8.0 \%)$ & $4(16.0 \%)$ & 0.490 \\
\hline Bleeding & $1(4.0 \%)$ & 0 & 0.667 \\
\hline Venous thrombosis & & & 1.000 \\
\hline $\begin{array}{l}\text { Postoperative Follow up } \\
\text { (After 1 month) }\end{array}$ & $6(24.0 \%)$ & $8(32.0 \%)$ & 0.754 \\
\hline Recurrent & & & \\
\hline
\end{tabular}

\section{Discussion}

Heller cardiomyotomy and endoscopic PD are the two main treatments for achalasia and disrupt the circular muscle of the LES. Peroral endoscopic myotomy is a new endoscopic technique that is gaining popularity in treating achalasia and other GI disorders, but it lacks reproducibility and long-term results assessing its efficacy; moreover, it needs training expertise and specialized centers that are not widely available. It is difficult to assess the superiority of one method to another because of the low disease prevalence. A few studies have compared both techniques in the management of achalasia and found similar efficacy and varying complications. The European Achalasia Trial group showed that the therapeutic success rate for LHM was similar to that of PD after 2 years of follow-up [13]. Some physicians consider PD to be the first-line management option because it can be performed on an outpatient basis with fewer complications, and LHCM is considered to be the second-line option after PD failure $[14,15]$. Hence, the main objective of this study was to use a randomized study design to evaluate the two state-of-the-art treatments, PD and LHCM.

We conducted this study in a sample of 50 patients diagnosed with achalasia and who had an Eckardt symptom score $>3$. The patients were randomly assigned to group A, which was treated by LHCM, and group $B$, which was treated by endoscopic PD. The patients' age, sex, and BMI were comparable between the two groups with no statistically significant differences shown. The symptom durations in groups $A$ and $B$ were $46.12 \pm 27.187$ and $52.84 \pm 30.449$ months, respectively, and there were no significant differences in occupation, comorbidity, and smoking habits between the groups. Our results are consistent with those of Boeckxstaens et al., [16], who conducted a study in 201 patients with idiopathic achalasia.

The current study showed a significant difference in the height of the barium-contrast column after 5 min at 16 months between the two groups, with lower height among patients in the LHCM group. Vela et al. demonstrated that the post-procedure reduction in the height of the barium column at $5 \mathrm{~min}$ is considered to be a predictor of success, especially in men, and lack of improvement carries a risk for repeating the surgical 
procedure [17] in contrast to a study by An Moonen et al. [6] that found no significant differences in the height of the barium-contrast column after $5 \mathrm{~min}$ at 1,2, and 5 years between the LHCM group and PD group. Another study reported by Boeckxstaens et al. [16] showed no significant differences in the height of the barium-contrast column after 5 min at 1 and 2 years between the two groups.

However, for the other parameters of the primary and secondary outcomes at 8 and 16 months of follow-up, our study has shown no significant difference in Eckardt scores between the studied groups. In contrast to our findings, the study of Boeckxstaensa et al. [16] found that the success rates after 1 and 2 years of followup were $93 \%$ and $90 \%$, respectively, for LHCM and were $90 \%$ and $86 \%$, respectively, for PD, when the cutoff point in the study was a decrease in the Eckardt scale scores to $\leq 3$ as the criterion for successful treatment.

Regarding quality of life, the current study showed no significant differences in the physical or mental component after 8 and 16 months of follow-up between the PD and LHM groups, which agrees with the findings of a study reported by An Moonen et al. [6] that showed no significant difference in the quality of life after 1,2, and 5 years of follow-up between the two groups. Another study reported by Boeckxstaens et al. [16] using the same SF-36 survey showed no significant difference in quality of life after 1 and 2 years of follow-up between the two groups. A study reported by Jan Persson et al. [7] using the Psychological General Well-being (PGWB) questionnaire showed that the total PGWB score was significantly higher in the LHM group than in the PD group after 3 years. The difference was evident in all domains, particularly for anxiety and self-control, but after 5 years, the difference was diminished.

The present study showed a significant difference in the LES pressure of $10.20 \pm 1.3$ and $14.00 \pm 1.6$ in the LHCM and PD groups, respectively, after 8 months of follow-up between the groups, which is consistent with the results of a study reported by Boeckxstaens et al. [16] that showed a significant difference after 1 year of follow-up between the two groups, with a higher LES pressure in the PD than in the LHCM group.Another study reported by An Moonen et al. [6] showed a significant difference in the LES pressure after 1 year of follow-up between the two groups, with a higher pressure in the PD group than in the LHCM group. In contrast to a study reported by Borges et al. [18] that showed no significant difference in the decrease in the LES pressure $<50 \%$ after 3 months of follow-up between the two groups, with $60.7 \%$ for the PD group and $85.7 \%$ for the LHCM group.

Effectiveness, durability of response, and procedure-related complications affect the choice of treatment. Among the entire surgical community, mucosal tears that immediately healed during surgery occur in $4 \%$ of patients. Esophageal perforation complications in PD were noted in $8 \%$ of patients, a rate that is comparable to that previously reported by Boeckxstaens et al. [16]. Esophageal perforation appeared in four (4\%) of the 95 patients in the PD group, which is comparable to that reported by Emad Hamdy et al. [9]. Esophageal perforation occurred in two (8\%) of the 50 patients, mucosal tears occurred in $12 \%$ in the LHCM group, and abnormal gastric acid toxicity occurred in $15 \%$ of the PD patients and $23 \%$ of the LHCM patients. On the other hand, symptom improvement for PD and LHCM patients who experienced gastroesophageal reflux events was higher but transient in the PD group than in the LHM group, which may be explained by the combination of the DOR fundoplication technique with Heller myotomy to minimize postoperative acid reflux in the LHCM group. Twenty-six percent of the patients included in the study by Vela MF et al. were on protonpump inhibitors at the last follow-up evaluation, and complicated GERD was rare (4\%); however, an anti-reflux 
procedure was performed in only $33 \%$ of those patients [17]. In a study by Emad Hamdy et al., $16 \%$ and $28 \%$ of patients developed reflux symptoms after PD and laparoscopic Heller myotomy, respectively [9].

The current study showed no significant difference in recurrence of symptoms after 1 month between the two groups, which were $24 \%$ and $32 \%$ in the LHCM and PD groups, respectively. These findings were comparable to those reported by Emad Hamdy et al. who found that the rates of recurrent symptoms after 1 year were $26.3 \%$ and $8.3 \%$ in the PD and LHCM groups, respectively [9].

The Kaplan-Meier curve analyses in the present study showed no significant difference in the treatment success rates between the two groups, although the numerical results were higher for the LHM group than for the PD group at 7, 10, and 15 months. Those findings agree with those of a study reported by An Moonen et al. [6] that showed no significant differences in the success rates of $94 \%$ for LHM and $90 \%$ for PD after 1 year, 89\% (LHCM) and 86\% (PD) after 2 years, and 84\% (LHM) and 82\% (PD) after 5 years of follow-up between the two groups. In contrast, another study reported by Jan Persson et al. [7] showed significant differences in the success rates of $96 \%, 96 \%, 92 \%$ and $88 \%$ for LHCM and of $79 \%, 68 \%, 64 \%$, and $61 \%$ for PD after $1,3,5$, and 6.5 years of follow-up, respectively, between the groups.

There were some study limitations that should be considered when interpreting the results. We performed our study in a single center, and the results could have been affected by the degree of operator experience. Other limitations included the small sample sizes of the studied groups and the lack of post-procedure motility studies.

\section{Conclusion}

This study showed that the therapeutic success rates of LHCM at different follow-up time points were not superior to those of PD, indicating that graded dilation starting with a $30-\mathrm{mm}$ balloon is an appropriate procedure for PD.

\section{List Of Abbreviations}

\begin{tabular}{|lll|}
\hline$\cdot$ & LHCM & laparoscopic Heller's cardiomyotomy with Dor's fundoplication \\
\hline$\cdot$ & LES & lower esophageal sphincter \\
\hline$\cdot$ & GERD & gastroesophageal reflux disease \\
\hline$\cdot$ & PD & Pneumatic dilatation \\
\hline$\cdot$ & BMI & Body Mass Index. \\
\hline
\end{tabular}

\section{Declarations}

Funding

No funding was received. 


\section{Ethical approval and consent to participate}

All procedures performed in our study involving human participants was in accordance with the ethical standards of the institutional and/or national research committee and with the 1964 Helsinki declaration and its later amendments or comparable ethical standards.

\section{Consent for publication}

We obtained consent from all the patients included in our study with institutional consent forms.

\section{Availability of data and materials}

The datasets used and/or analyzed during the current study are available from the corresponding author on reasonable request. All data generated or analyzed during this study are included in this published article [and its supplementary information files].

\section{Competing interests}

The authors declare that they have no competing interests.

\section{Authors' contributions}

IK, GMB,MF carried out and participated in the surgical procedures, MS carried out the pneumatic dilatation. MF, IK, MS conceived the study, participated in study design and sequence alignment, and drafted the manu script. S Abdulaziz, LSO\&S Alshafie helped to draft and critically revise the manuscript. GMB \& IK participated in data collection and performance of the statistical analysis. S Abdulaziz, LSO\&S Alshafie participated in study coordination, and critical revision. All authors have read and approved the final manuscript.

\section{Acknowledgments}

We would like to give special thanks, admiration, and respect to all our department members for their kind help, guidance and valuable support.

\section{References}

1. Aiolfi A, Bona D, Riva CG, Micheletto G, Rausa E, Campanelli G, et al. Systematic review and Bayesian network meta-analysis comparing laparoscopic Heller myotomy, pneumatic dilatation, and peroral endoscopic myotomy for esophageal Achalasia. J Laparoendosc Adv Surg Tech. 2020;30(2):1-9.

2. O'Neill OM, Johnston BT, Coleman HG. Achalasia: A review of clinical diagnosis, epidemiology, treatment, and outcomes. World J Gastroenterol. 2013;19(35):5806-12. 
3. Kessing BF, Bredenoord AJ, Smout AJPM. Erroneous diagnosis of gastresophageal reflux disease in achalasia. Clin Gastroenterol Hepatol. 2011;9(12):1020-4.

4. Schlottmann F, Herbella F, Allaix ME, Patti MG. Modern management of esophageal achalasia: From pathophysiology to treatment. Curr Probl Surg. 2018;55(1):10-37.

5. Wu JCY. Pneumatic dilation versus laparoscopic Heller's myotomy for idiopathic achalasia. J Neurogastroenterol Motil. 2011;17(3):324-6.

6. Moonen A, Annese V, Belmans A, Bredenoord AJ, Varannes SB Des, Costantini M, et al. Long-term results of the European Achalasia trial: A multicentre randomized controlled trial comparing pneumatic dilation versus laparoscopic Heller myotomy. Gut. 2016;65(5):732-9.

7. Persson J, Johnsson E, Kostic S, Lundell L, Smedh U. Treatment of achalasia with laparoscopic myotomy or pneumatic dilatation: Long-term results of a prospective, randomized study. World J Surg. 2015;39(3):713-20.

8. Schlottmann F, Patti MG. Laparoscopic heller myotomy versus per oral endoscopic myotomy: Evidencebased approach to the treatment of esophageal achalasia. Am Surg. 2018;84(4):496-500.

9. Hamdy E, El Nakeeb A, El Hanfy E, El Hemaly M, Salah T, Hamed H, et al. Comparative study between laparoscopic Heller Myotomy versus pneumatic dilatation for treatment of early Achalasia: A prospective randomized study. J Laparoendosc Adv Surg Tech. 2015;25(6):460-4.

10. Herbella FAM, Moura EGH, Patti MG. Achalasia 2016: Treatment Alternatives. J Laparoendosc Adv Surg Tech. 2017;27(1):6-11.

11. Brazier JE, Harper R, Jones NM, et al. Validating the SF-36 health survey questionnaire: new outcome measure for primary care. BMJ 1992;305:160-4.

12. Blazeby JM, Alderson D, Winstone K, et al. Development of an EORTC questionnaire module to be used in quality of life assessment for patients with esophageal cancer. Eur J Cancer 1996;32A:1912.

13. 10.1056/NEJMoa1010502.

14. Lynch KL, Pandolfino JE, Howden CW, Kahrilas PJ. Major complications of pneumatic dilation and Heller myotomy for achalasia: single center experience and systematic review of the literature. The American journal of gastroenterology, 2012;107.

15. Spechler, S. J. (2011). Pneumatic dilation and laparoscopic Heller's myotomy equally effective for achalasia. The New England journal of medicine, 364(19), 1868.

16. Boeckxstaens GE, Annese V, des Varannes SB, et al. Pneumatic dilation versus laparoscopic Heller's myotomy for idiopathic achalasia. N Engl J Med. 2011;364(19):1807-doi:10.1056/NEJMoa1010502.

17. Vela MF, Richter JE, Khandwala F, The long-term efficacy of pneumatic dilatation and Heller myotomy for the treatment of achalasiaClin Gastroenterol Hepatol 2006; 4:580-587.

18. Borges, A. A., Lemme, E. D. O., Abrahao Jr, L. J., Madureira, D., Andrade, M. S., Soldan, M., \& Helman, L. (2014). Pneumatic dilation versus laparoscopic Heller myotomy for the treatment of achalasia: variables related to a good response. Diseasesof the Esophagus, 27(1), 18-23.

\section{Figures}



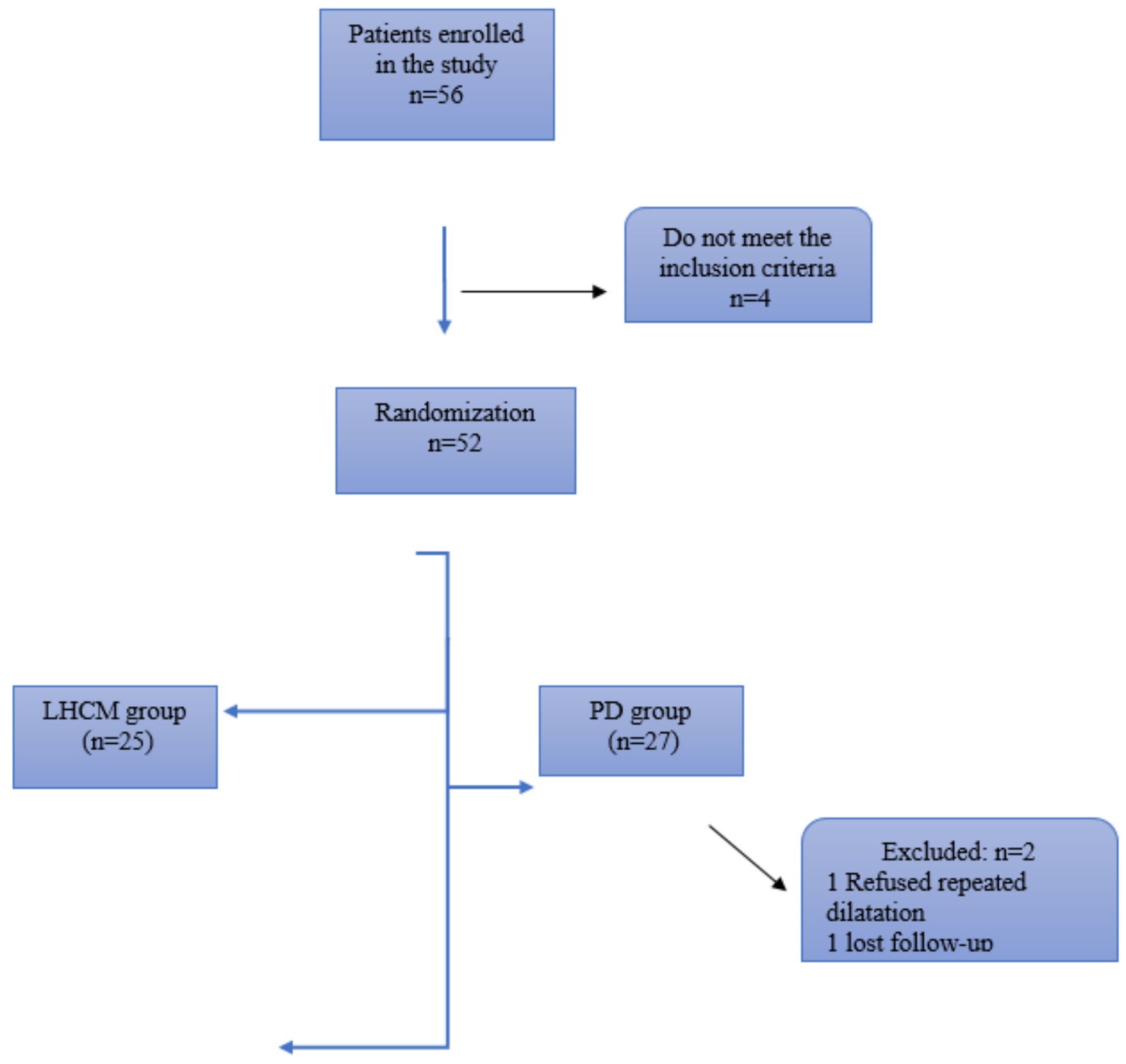

Final Analysis $\mathrm{n}=25$

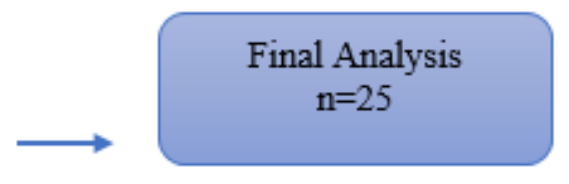

Figure 1

Flow chart of study sample, from 56 patients enrolled in the study , 52 patients were fit into the inclusion and exclusion criteria and 50 patients completed the study ( 25 in each group). 


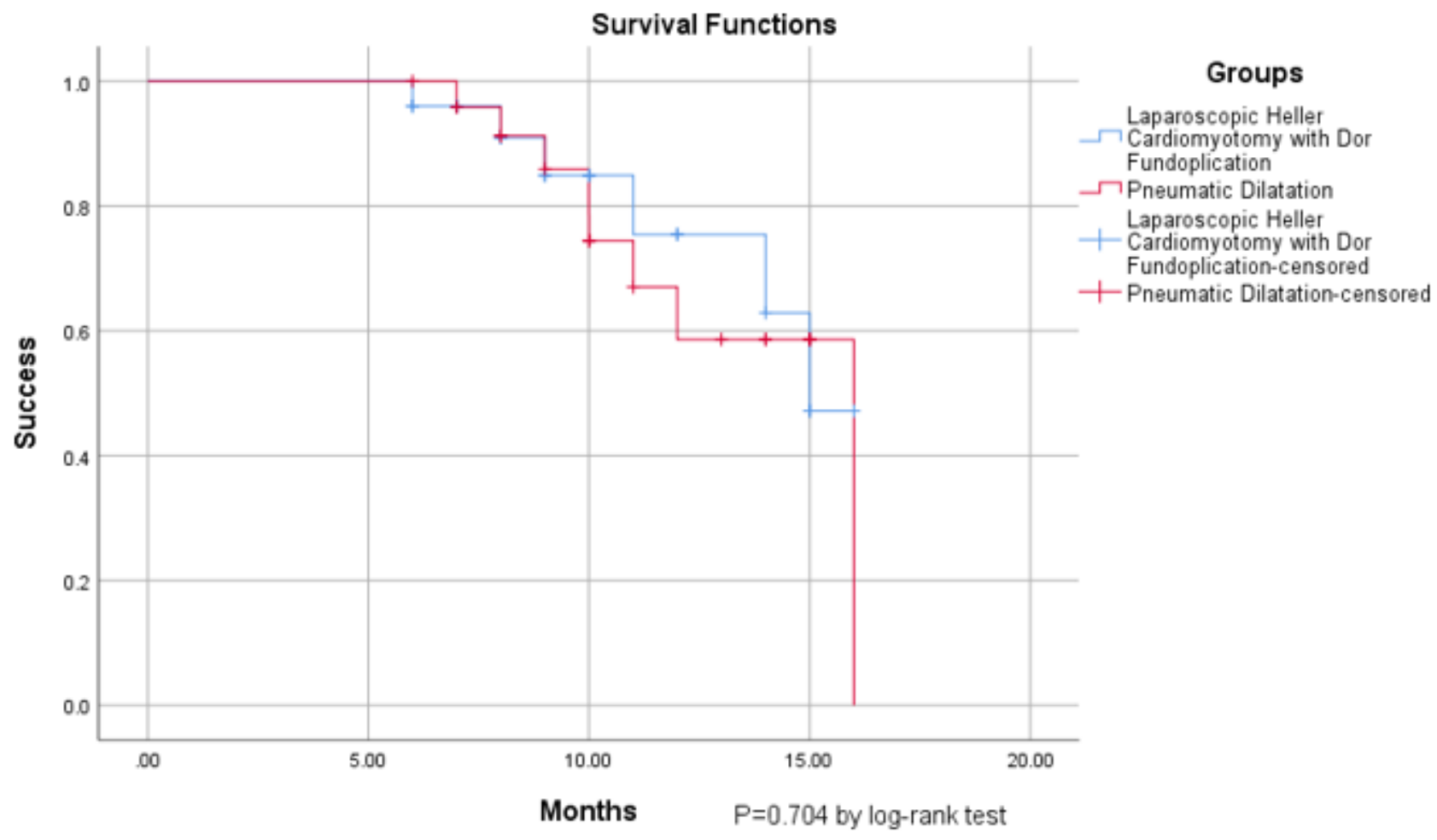

Figure 2

Kaplan-Meier Curves of the survival functions of achalasia patients who either underwent LHCM or PD $(P=0.704)$. 